\title{
ESTUDO DO EFEITO DA DENSIDADE NAS PROPRIEDADES DE UM MATERIAL FERROSO COM GRADIENTE DE FUNÇÃO
}

\author{
Renata Komata ${ }^{\text {* }}$ \\ Flavio Beneduce Neto ${ }^{2}$
}

\section{Resumo}

Existem diversos componentes produzidos por metalurgia do pó que necessitam utilizar uma matéria prima nobre devido a aplicações que causam desgaste em áreas específicas. Desta forma faz-se necessário o desenvolvimento de um material tornado o projeto mais atraente economicamente. $\mathrm{O}$ objetivo deste trabalho é analisar e discutir o efeito da densidade nas propriedades mecânicas e microestruturais de materiais com gradiente de função compostos por metade de ferro comercialmente puro e a outra metade de um aço baixa liga contendo Mo e Cu para tratamento de sinterhardening. Corpos de prova foram compactados variando-se a densidade, sinterizados e revenidos. Ensaios de tração, análise metalográfica e dureza foram realizados. Foi possível verificar, de acordo com os resultados, que o aumento da densidade promove o aumento das propriedades mecânicas, assim como a dureza. Desta forma, é possível fabricar componentes com esta composição levando-se em consideração a distância referente a zona de transição para que as propriedades necessárias estejam presentes nas regiões críticas.

Palavras-chave: Metalurgia do pó; Densidade; Sinterhardening.

\section{DENSITY EFFECT STUDY ON THE PROPERTIES OF A FERROUS MATERIAL WITH FUNCTION GRADIENT}

\begin{abstract}
There are several components produced by powder metallurgy that need to use a noble raw material due to applications that cause wear in specific areas. In this way it is necessary to develop a material made the project more economically attractive. The objective of this work is to analyze and discuss the effect of density on the mechanical and microstructural properties of functionally gradient materials composed of half of commercially pure iron and the other half of a more noble material containing specific alloying elements for the treatment of sinterhardening. Test specimens were compacted by varying the density, sintered and tempered. Tensile strength, metallographic analysis and hardness were performed. It was possible to verify, according to the results, that the increase of the density promotes the increase of the mechanical properties, as well as the hardness. In this way, it is possible to fabricate components with this composition taking into account the distance of the transition zone so that the necessary properties are present in the critical regions. Keywords: Powder metallurgy; Density; Sinterhardening.
\end{abstract}

\section{INTRODUÇÃO}

A metalurgia do pó é um processo recente, quando comparado com os outros utilizados no processamento de metais. A sua utilização apresenta amplas vantagens sobre os outros processos como o aproveitamento da matéria-prima acima de $95 \%$, a fabricação de altos volumes de peças com geometria complexa, altas tolerâncias dimensionais, ótimo acabamento superficial, entre outras [I].
Devido à flexibilidade da obtenção de diferentes composições químicas, formas e do processamento em si, a metalurgia do pó é amplamente utilizada em segmentos como a indústria automobilística, eletrodomésticos, filtros metálicos, materiais de fricção, buchas auto-lubrificantes, etc [2].

Ligas especiais, normalmente de maior custo, são utilizadas para obter propriedades mais elevadas, aumentando

'Universidade Presbiteriana Mackenzie, São Paulo, SP, Brasil.

${ }^{2}$ Departamento de Engenharia Metalúrgica e de Materiais, Escola Politécnica, Universidade de São Paulo - USP, São Paulo, SP, Brasil.

*Autor correspondente: r_komata@hotmail.com

21 76-I 523 (C) 2020. Komata et al. Publicado pela ABM. Este é um artigo publicado em acesso aberto (Open Access) sob a licença Creative commons Attribution, que permite uso, distribuição e reprodução em qualquer meio, sem restrições desde que o trabalho original seja corretamente citado. 


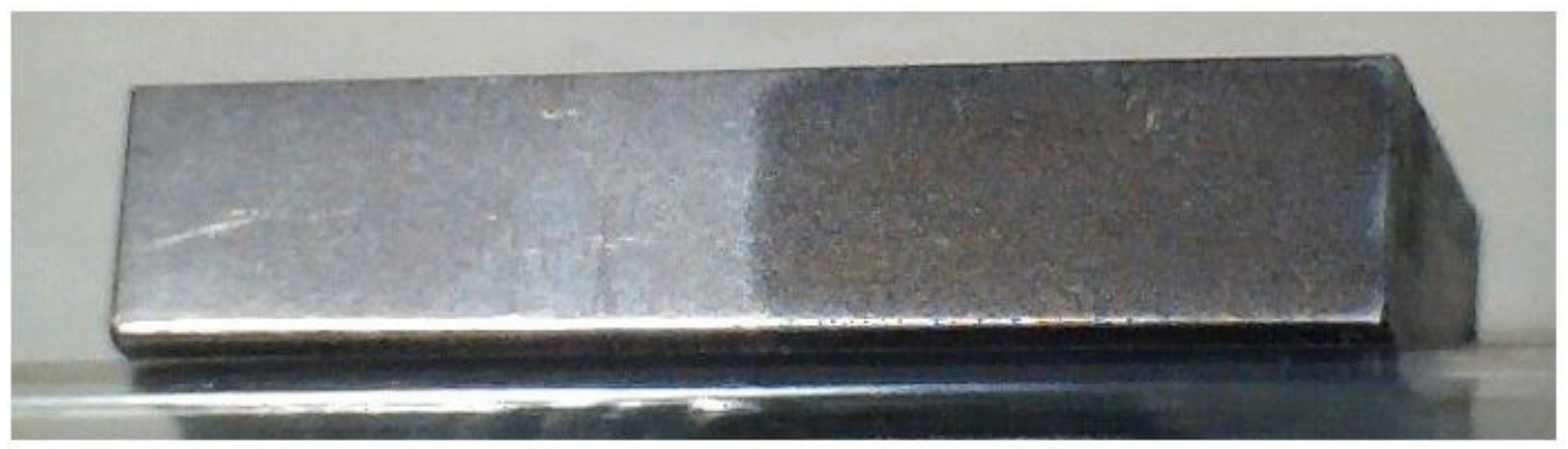

Figura I. Corpos de prova com gradiente de função.

Tabela I. Composição química em massa das ligas utilizadas para a produção dos corpos de prova

\begin{tabular}{cc}
\hline Mistura I & Mistura 2 \\
\hline 100\% Ferro* & Ferro (balanço) \\
& I, I6\% Molibdênio \\
& $2,00 \%$ Cobre \\
& $0,80 \%$ Grafite \\
\hline
\end{tabular}

*nominal.

o custo do projeto. Algumas aplicações podem requerer peças que apresentem alta dureza e resistência em somente alguma região específica. Em peças fundidas essa condição de gradiente de função é obtida por um tratamento térmico localizado como, por exemplo, a têmpera por indução.

O objetivo deste trabalho é analisar e discutir o efeito da densidade nas propriedades mecânicas e microestruturais de materiais com gradiente de função compostos por metade de ferro comercialmente puro e a outra metade de um material mais nobre, que contém elementos de liga específicos para tratamento de sinterhardening'.

\section{MATERIAIS E MÉTODOS}

Para a preparação das misturas, foram utilizados os seguintes materiais: pó de cobre, pó de grafite, pó de ferro atomizado e pó de ferro pré-ligado com composição comercial ( $1,2 \%$ de molibdênio e $98,8 \%$ de ferro), além do lubrificante sólido para alta densidade (Kenolube).

A partir dos materiais base, foram preparadas 2 misturas. Os componentes foram pesados, de forma que as misturas finais apresentaram as composições químicas descritas na Tabela I. Para a homogeneização dos materiais, utilizou-se um misturador em "V" para amostras com capacidade de $3 \mathrm{~kg}$ por batelada. A mistura foi homogeneizada por 15 minutos.

\footnotetext{
I Tratamento de térmico de endurecimento durante a etapa de sinterização da peça através do aumento da taxa de resfriamento do forno de sinterização. Desta forma, uma porção significativa do material se transforma em martensita, eliminando a necessidade de um tratamento térmico adicional [3].
}

Foram compactados corpos de provas, nas densidades de $6,4,6,7$ e $7,0 \mathrm{~g} / \mathrm{cm}^{3}$, tanto retangulares (conforme norma MPIF Standard 4I [4]) como corpos de prova para o ensaio de tração (conforme norma MPIF Standard I0 [4]). As dimensões aproximadas dos corpos de provas eram $31,7 \mathrm{~mm}, 12,7 \mathrm{~mm}$ e 6,35 mm de comprimento, largura e altura, respectivamente, Em ambos os casos, o enchimento foi manual e para a compactação dos corpos de prova com gradiente de função, utilizou-se uma "sapata" com uma divisória interna a fim de que não houvesse a mistura dos pós-base antes destes escoarem para dentro da matriz, de forma que metade do corpo de prova fosse composto pela mistura I e a outra metade pela mistura 2 e uma pequena região de interface fosse formada, como pode ser visualizado na Figura I. A matriz de corpos de prova, assim como a sapata utilizada para os corpos de prova retangulares podem ser visualizados na Figura 2.

Todos os corpos de prova (retangulares e para os utilizados no ensaio de tração) foram sinterizados à $1120^{\circ} \mathrm{C}$, por 22,5 minutos com taxa de resfriamento de aproximadamente $2,4^{\circ} \mathrm{C} / \mathrm{s}$. A atmosfera era composta por $90 \%$ de nitrogênio e $10 \%$ de hidrogênio e apresentava ponto de orvalho de $-18^{\circ} \mathrm{C}$. Após sinterizados, os corpos de prova foram revenidos à $190^{\circ} \mathrm{C}$ por I hora.

Para a verificação da diferença das densidades do lado do corpo de prova composto por ferro puro e do lado composto pelo material ligado, corpos de prova verdes, antes da sinterização, foram cortados na região de transição utilizando-se uma cortadora de fita e a densidade de cada uma das metades foi medida, conforme norma MPIF Standard 42 [4]. Além disso, a densidade de corpos de prova inteiros também foi determinada.

Para a realização do ensaio de resistência à tração foi utilizada uma máquina universal e o ensaio foi realizado com base na norma MPIF Standard I0 [4].

Para efetuar o ensaio de dureza, os corpos de prova foram lixados, superficialmente, com lixa \#400 somente para a remoção de possíveis rebarbas que pudessem influenciar no resultado da medição. $O$ ferro comercialmente puro apresenta menor macrodureza, quando comparado com a liga, além da variação da densidade que influencia 


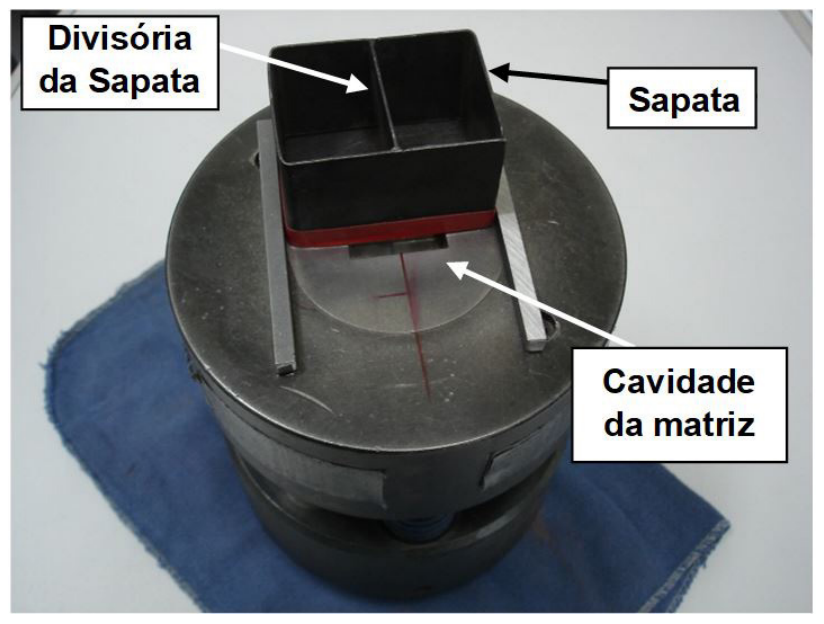

Figura 2. Matriz de corpos de provas retangular e sapata com divisória interna.

nos resultados dos ensaios. Por esta razão, duas escalas diferentes de macrodureza foram utilizadas. A macrodureza no ferro foi medida em HRF, escala suficiente para medir nas 3 densidades, com valores representativos. No caso da liga, a macrodureza foi medida em HRA, indicada para materiais que sofreram tratamento térmico.

Para avaliação metalográfica, os corpos de prova foram cortados longitudinalmente, lixados com lixas 220, $320,400,600,1000$ e polidos primeiramente com alumina I $\mathrm{mm}$ e posteriormente com pasta de diamante de $0,3 \mathrm{~mm}$. Realizou-se a avaliação dos corpos de prova sem ataque a fim de verificar possíveis diferenças de densidade e a morfologia da porosidade em cada uma das misturas. Em seguida, eles foram atacados com solução de Nital $2 \%$ e a microestrutura foi avaliada.

Foram comparadas as propriedades mecânicas dos materiais individuais com as propriedades mecânicas das zonas de transição das peças (corpos de prova) compostas por metade do material puro e a outra metade pelo material ligado. As propriedades mecânicas que foram estudadas são a resistência à tração, a resistência à ruptura transversal, a dureza ao longo dos corpos de prova. Foram feitas análises metalográficas, associando-as à microdureza e à variação da densidade ao longo dos corpos de prova como resposta às diferentes compressibilidades dos materiais puros.

\section{RESULTADOS E DISCUSSÕES}

Os resultados das diferenças de densidade das metades dos corpos de prova com gradiente de função, assim como a densidade total medida em corpos de prova inteiros podem ser verificados na Tabela 2 .

Foi possível verificar que as metades dos corpos de prova compostas pela mistura I (ferro comercialmente puro) apresentam maior densidade do que as metades compostas pela mistura 2 (material ligado).
Tabela 2. Densidades das metades dos corpos de prova com gradiente de função

\begin{tabular}{ccc}
\hline $\begin{array}{c}\text { Densidade Total } \\
\left(\mathbf{g} / \mathbf{c m}^{3}\right)\end{array}$ & $\begin{array}{c}\text { Densidade } \\
\text { metade - mistura } \\
\text { I }\left(\mathbf{g} / \mathbf{c m}^{3}\right)\end{array}$ & $\begin{array}{c}\text { Densidade } \\
\text { metade - mistura } \\
\mathbf{2}\left(\mathbf{g} / \mathbf{c m}^{3}\right)\end{array}$ \\
\hline $6,40 \pm 0,0 \mathrm{I}$ & $6,46 \pm 0,0 \mathrm{I}$ & $6,33 \pm 0,0 \mathrm{I}$ \\
$6,70 \pm 0,0 \mathrm{I}$ & $6,75 \pm 0,0 \mathrm{I}$ & $6,65 \pm 0,0 \mathrm{I}$ \\
$7,00 \pm 0,0 \mathrm{I}$ & $7,04 \pm 0,0 \mathrm{I}$ & $6,95 \pm 0,0 \mathrm{I}$ \\
\hline
\end{tabular}

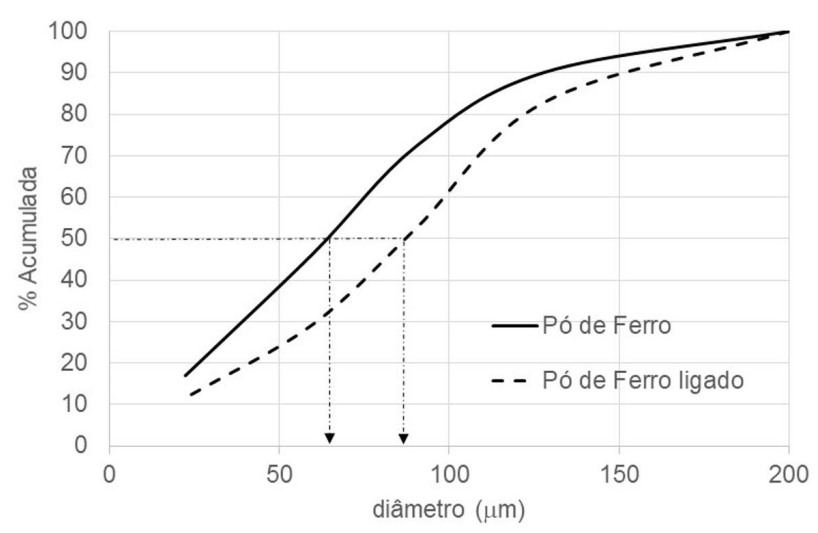

Figura 3. Comparativo da distribuição granulométrica acumulada dos pós de ferro atomizado e pré-ligado. As setas indicam o D50 dos pós utilizados.

Tabela 3. Caracterização das misturas

\begin{tabular}{cc}
\hline Material & Densidade aparente $\left(\mathrm{g} / \mathrm{cm}^{3}\right)$ \\
\hline Mistura I & $3,26 \pm 0,0 \mathrm{I}$ \\
Mistura 2 & $3,17 \pm 0,01$ \\
\hline
\end{tabular}

A distribuição granulométrica é um dos fatores que influenciam a compressibilidade do material. $O$ fato da mistura I apresentar um maior percentual de finos, como pode ser visto na Figura 3, contribuiu para a densidade maior do lado composto por este material. O valor de D50 do pó de ferro possui aproximadamente 20 micra de diferença do pó de ferro ligado.

Outro fator que explica a diferença de densidade entre os dois materiais é a densidade aparente das misturas. Após caracterização das misturas obtidas, as densidades aparentes encontradas estão mostradas na Tabela 3.

Desta forma, o fato da mistura I apresentar maior densidade aparente resulta em uma maior quantidade de material nesta metade do corpo de prova com gradiente de função, isto é o lado composto pela mistura I contém mais material que a metade composta pela mistura 2.

Além disso, o fato da mistura 2 conter em sua composição molibdênio como elemento de liga torna suas partículas mais duras que as partículas da mistura I composta por ferro comercialmente puro.

Desta forma, a diferença de densidade entre as duas metades é um reflexo da diferença de compressibilidade entre os dois materiais. Essa diferença, como discutido anteriormente é resultante de diversos fatores como a 
distribuição granulométrica, a densidade aparente e a composição química dos materiais [5].

Após a sinterização foi também possível observar a diferença de densidade entre os materiais. Neste caso, além do exposto acima, o que justifica a maior densidade do lado composto pelo ferro puro é que a mistura 2 contém em sua composição cobre, que expande na sinterização [2], enquanto o ferro puro contrai [6]. Isso pode ser conferido na Tabela 4. O mesmo fenômeno foi verificado nos corpos de prova com gradiente de função.

Avaliando-se a variação dimensional de acordo com a densidade do compactado, no caso da mistura I, é possível observar que a contração diminuiu com o aumento da densidade, enquanto na mistura 2 , a expansão aumentou.

Através da análise metalográfica dos corpos de prova com gradiente de função, foi possível visualizar a linha de transição entre os dois materiais com grande facilidade, já que os corpos de prova são compostos por metade de ferro comercialmente puro e a outra metade por um material ligado, como pode ser visto na Figura 4. Pode-se identificar os materiais pela porosidade. A região com maior porosidade é composta pela mistura 2, uma vez que já foi determinado que a mistura 2 possui menor densidade aparente. Consequentemente a região com menor porosidade é composta pela mistura I. A linha de transição pode ser visualizada de forma similar tanto nos

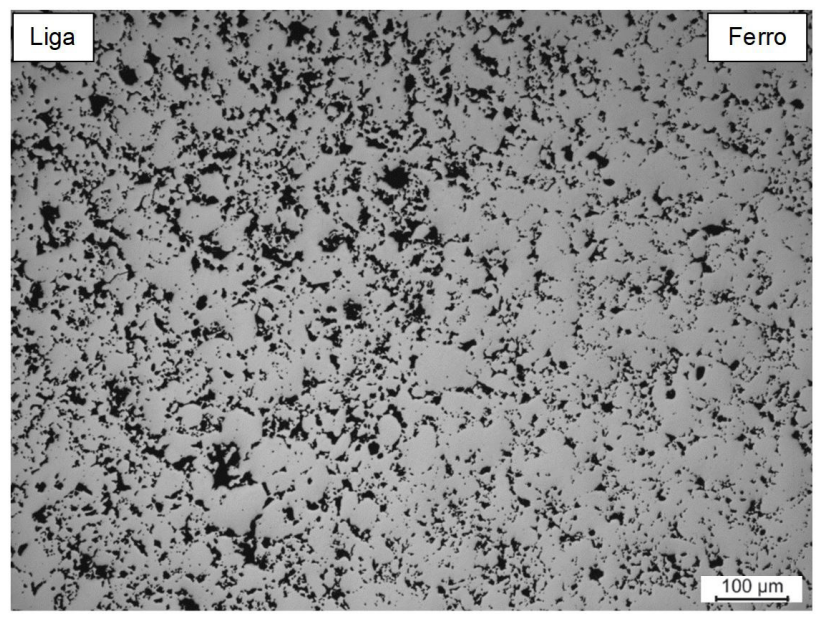

Figura 4. Seção transversal de um corpo de prova com gradiente de função com densidade de $7,0 \mathrm{~g} / \mathrm{cm}^{3}$, sem ataque.

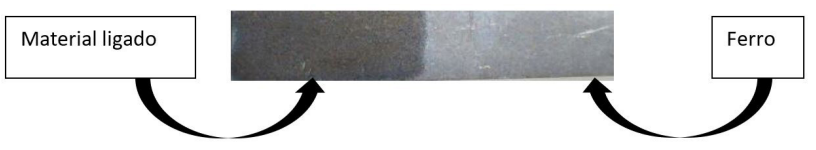

Figura 5. Corpo de prova com gradiente de função. corpos de prova com densidade de $6,4 \mathrm{~g} / \mathrm{cm}^{3}$ como nos de $6,7 \mathrm{~g} / \mathrm{cm}^{3}$ e $7,0 \mathrm{~g} / \mathrm{cm}^{3}$.

Após ataque metalográfico com Nital $2 \%$ do corpo de prova com gradiente de função, visualizado na Figura 5, foi possível verificar claramente a região de transição já que o material ligado (mistura 2) ataca com mais facilidade durante a preparação metalográfica.

A região de transição pode também ser observada nos corpos de prova atacados apresentados na Figura 6 a. $\mathrm{Na}$ mesma amostra na região do material ligado, a uma distância maior que aproximadamente $2,0 \mathrm{~mm}$, pode-se observar a presença predominante de martensita com regiões bainíticas, como apresentado na Figura 6b.

Ao se aproximar da interface, o material ligado torna-se cada vez mais bainítico pelo empobrecimento em carbono (difunde-se para o lado do ferro) como pode
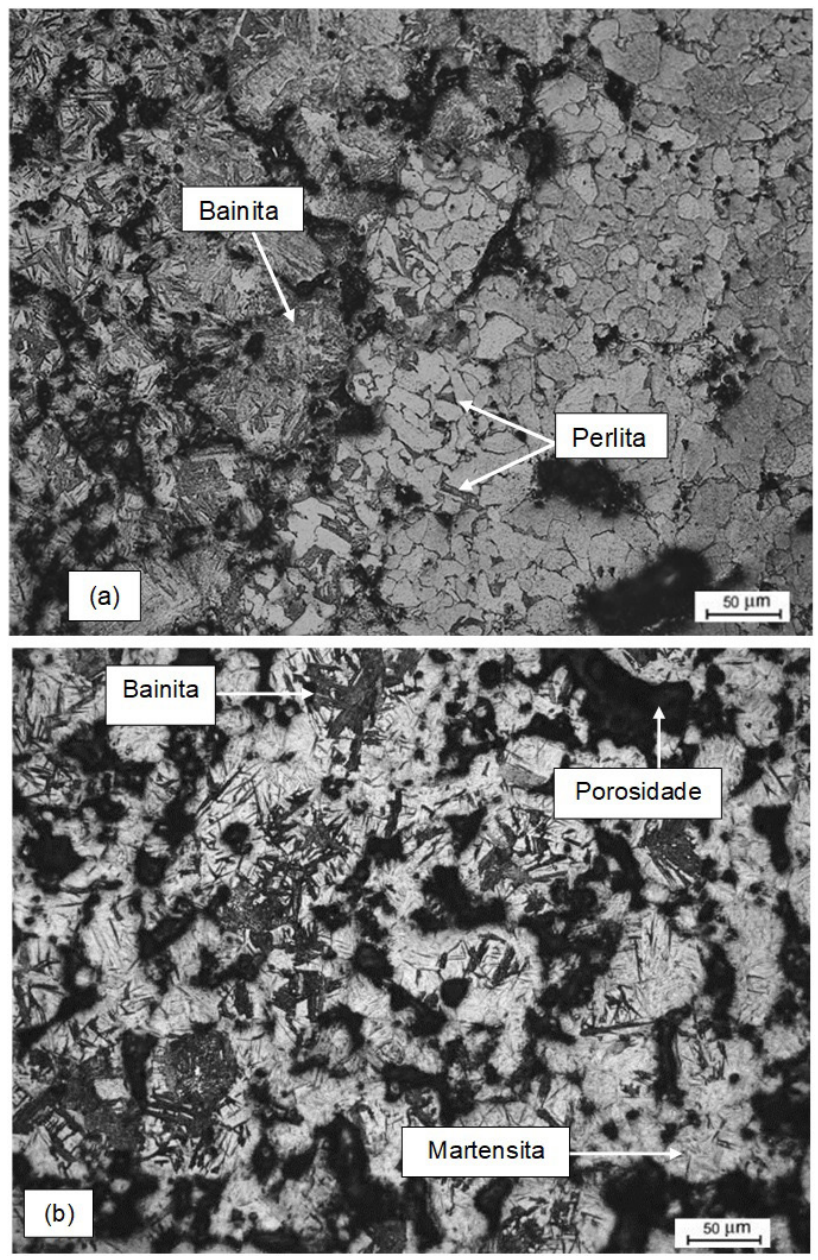

Figura 6. Seção transversal de um corpo de prova de densidade de $6,7 \mathrm{~g} / \mathrm{cm}^{3} \mathrm{com}$ gradiente de função atacado com Nital $2 \%$. (a) vista geral; (b) lado do ferro ligado.

Tabela 4. Variação dimensional dos corpos de prova

\begin{tabular}{|c|c|c|c|c|c|c|}
\hline & \multicolumn{3}{|c|}{ Mistura I } & \multicolumn{3}{|c|}{ Mistura 2} \\
\hline & I.I & 1.2 & 1.3 & 2.1 & 2.2 & 2.3 \\
\hline Variação dimensional (\%) & $-0,25 \pm 0,03$ & $-0,20 \pm 0,03$ & $-0,13 \pm 0,03$ & $0,36 \pm 0,03$ & $0,4 I \pm 0,03$ & $0,46 \pm 0,03$ \\
\hline
\end{tabular}


ser observado na Figuras 6. Do lado do ferro perto da interface, pela mesma razão, foi possível observar regiões perlíticas (Figura 6a e Figura 7a). Ao afastar-se da interface a microestrutura observada era $100 \%$ ferrítica, como pode ser visualizado na Figura 7b.

Em todas as densidades foi possível observar a formação de microestrutura semelhante à apresentada nas figuras, com todas as variações. A única diferença entre elas é a redução da porosidade à medida que a densidade da amostra aumentava.

A dureza foi medida ao longo dos corpos de prova, sendo a posição - 14 a extremidade do corpo de composta pela mistura 2 (material ligado), a posição 0 representa a interface e a posição +14 a extremidade composta pela mistura I (ferro comercialmente puro), como pode ser visualizado na Figura 8, após ataque com Nital 2\%. Os resultados do ensaio de dureza HRA estão representados na Figura 9.

A Figura 9 apresenta os resultados dos ensaios de dureza na extremidade composta por ferro comercialmente puro com valor nulo quando medida na escala HRA. Por essa razão, na extremidade da região do ferro (posição + I4) realizou-se medidas de dureza na escala HRF.

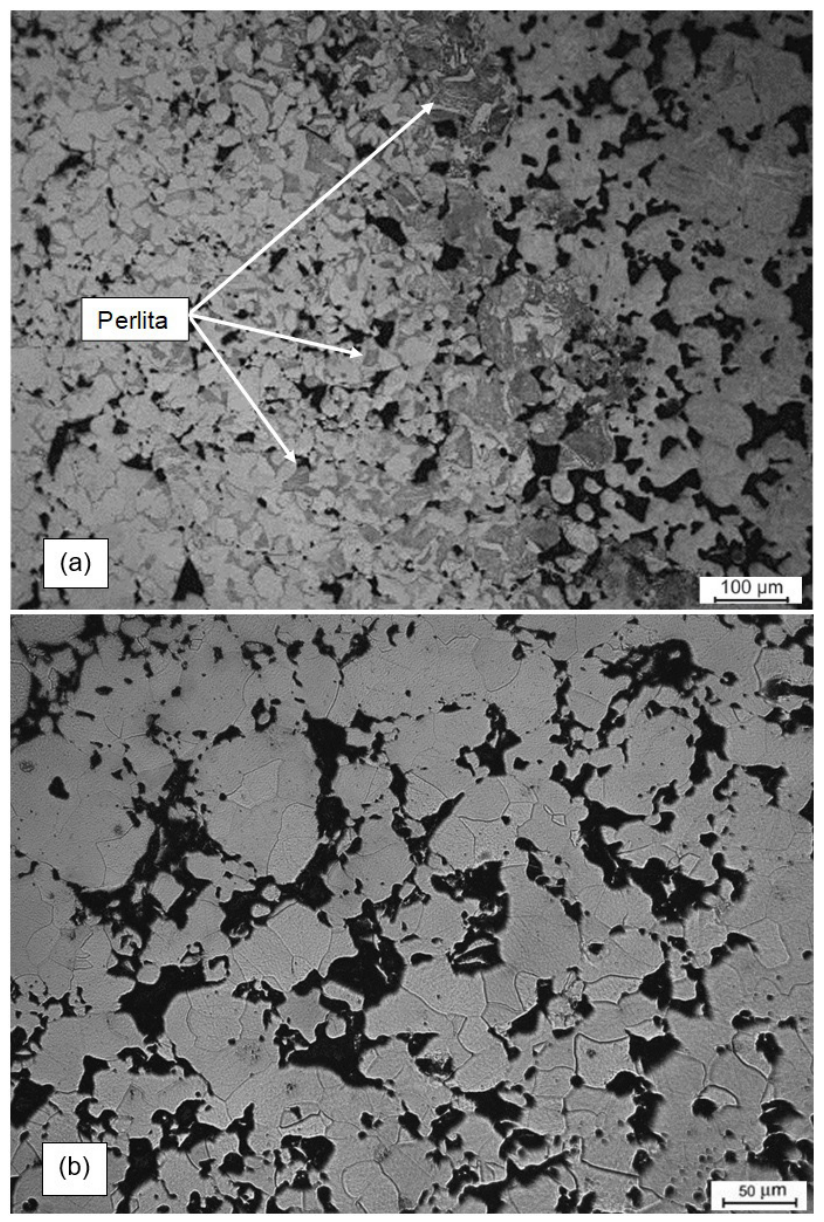

Figura 7. Seção transversal de um corpo de prova com gradiente de função atacado com Nital $2 \%$. (a) Região da interface numa posição diferente da Figura $6 \mathrm{a}$ - densidade de $6,7 \mathrm{~g} / \mathrm{cm}^{3}$; (b) Longe da interface do lado do ferro - densidade $6,4 \mathrm{~g} / \mathrm{cm}^{3}$.
Como pode ser observado nas Figuras 9 e 10, os corpos de prova com maior densidade apresentam maiores durezas, independente da escala utilizada - HRA e HRF [7]. Além disso, as extremidades compostas pelo material ligado apresentam maiores durezas, assim como as extremidades compostas pelo ferro puro apresentam os menores valores.

Pode-se observar que o comportamento da dureza foi semelhante em todas as densidades. Observando o lado do corpo de prova composto pelo material ligado, há aproximadamente $2 \mathrm{~mm}$ da zona de transição ocorre uma ligeira redução da dureza, tornando-se mais acentuada

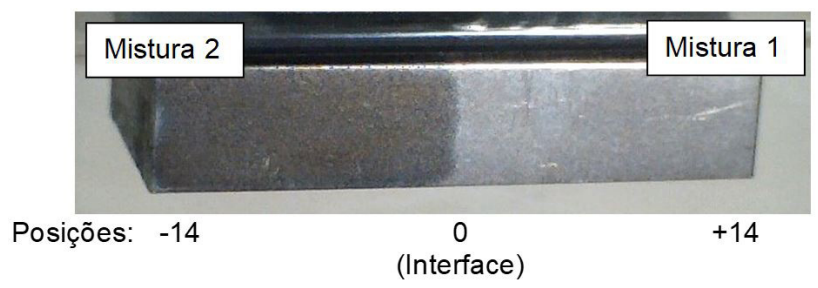

Figura 8. Corpo de prova com gradiente de função e as posições referentes aos ensaios de dureza.

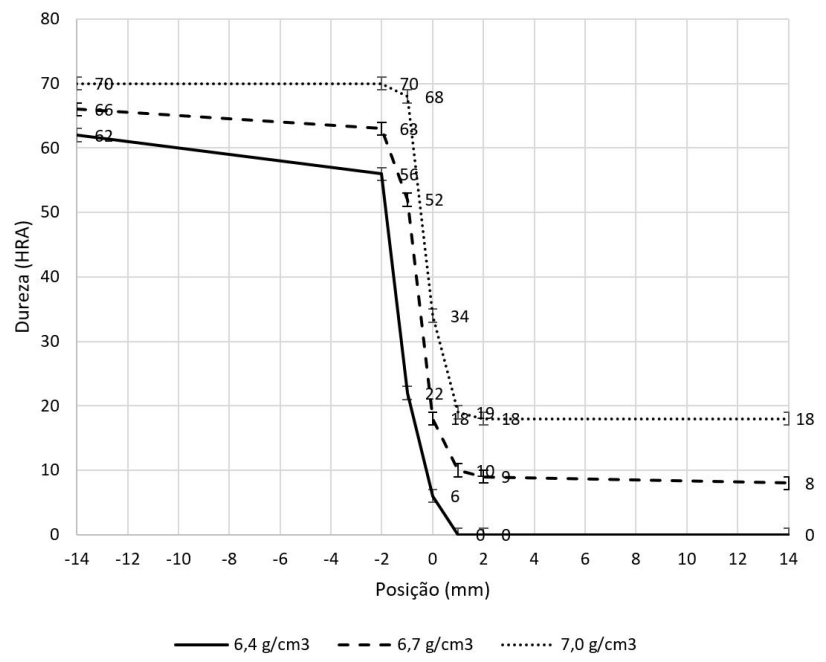

Figura 9. Resultados dos ensaios de macrodureza - HRA.

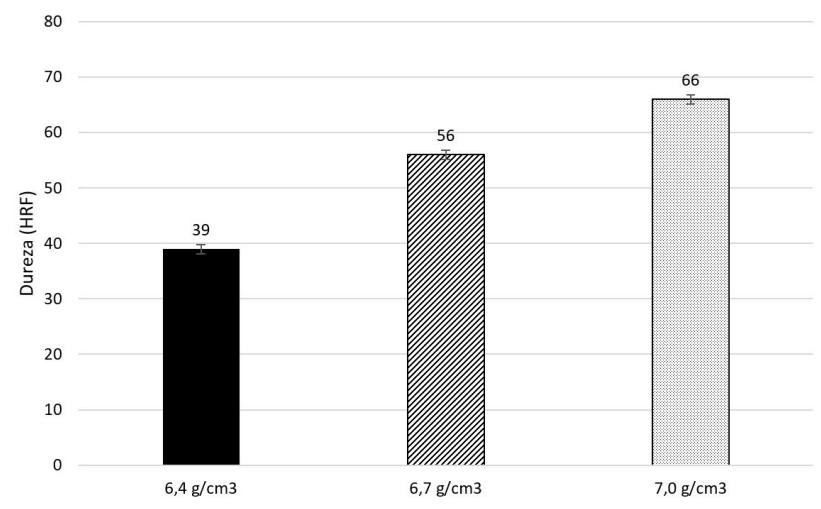

Figura 10. Resultados dos ensaios de dureza (HRF) na posição + I4 (extremidade do lado do ferro). 


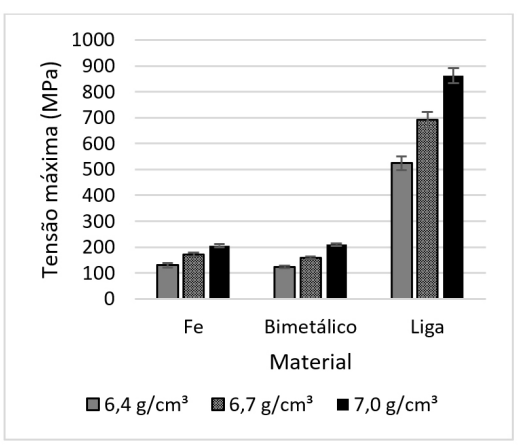

(a)

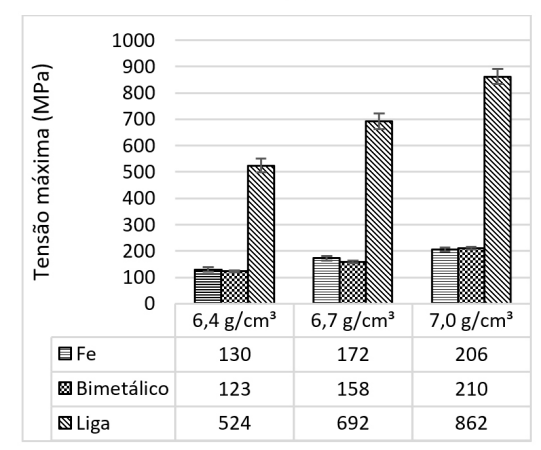

(b)

Figura I I. Resultados dos ensaios de resistência à tração. (a) Em relação ao material; (b) Em relação à densidade.

há aproximadamente $1,5 \mathrm{~mm}$ de distância desta região. Ao observar o lado do corpo de prova composto pelo ferro puro, o mesmo comportamento ocorre, porém há cerca de I mm de distância a dureza apresentada é praticamente a mesma que a da extremidade. Esses gradientes de dureza ocorrem devido a uma possível difusão dos elementos de liga de um material para o outro.

A dureza é maior do lado composto pelo material ligado devido à presença dos elementos de liga, que possibilitam, após tratamento térmico de sinterhardening, a formação de uma microestrutura majoritariamente martensítica, observada nas análises microestruturais realizadas anteriormente [8].

Em relação ao ensaio de tração, comparando-se os corpos de prova compostos pelos diferentes materiais e $o$ com gradiente de função (bimetálico), observou-se que os corpos de prova compostos por ferro puro apresentaram os menores valores de resistência à tração, os compostos pelo material ligado apresentaram os maiores valores e os com gradiente de função (bimetálicos) são similares aos valores do ferro comercialmente puro, como pode ser observado na Figura I l a. Avaliando-se a resistência à tração em relação à variação da densidade dos copos de prova para o mesmo material, os de maior densidade apresentaram maior resistência à tração que os de menor densidade por apresentarem menor porosidade e consequentemente uma maior porção de material em contato, como pode ser observado na Figura I I b.

\section{CONCLUSÕES}

De acordo com o que foi discutido neste trabalho, pode-se concluir que:

- é possível a produção de um material com gradiente de função a fim de reduzir o custo de produção para aplicações específicas sem perda das propriedades da peça;

- o aumento da densidade aprimora as propriedades avaliadas;

- cuidados devem ser tomados no projeto da peça com gradiente de função, como a localização da zona de transição entre os dois materiais, já que esta apresenta resistência mecânica similar ao material menos nobre.

\section{REFERÊNCIAS}

I Cremonezi A. A metalurgia do pó: alternativa econômica com menor impacto ambiental. São Paulo: Metallum Eventos Técnicos; 2009.

2 Chiaverini V. Metalurgia do pó. São Paulo: Associação Brasileira de Metalurgia do Pó; $200 \mathrm{I}$.

3 ASTM International. Standard terminology of powder metallurgy. West Conshohocken: ASTM International, 2012.

4 Metal Powder Industries Federation. Standard test methods for metal powders and powder metallurgy products. Princeton: MPIF; 1999.

5 Upadhyaya A, Upadhyaya GS. Powder metallurgy - science, technology and materials. India: Universities Press; 201 I.

6 Warzel RT, Neilan A. Effect of composition and processing on the precision of sinterhardening powder metal (PM) steel. Hollsopple, Pennsylvania: North American Hoganas Inc.; 2013.

7 Chagnon F, Trudel Y. Effect of density on mechanical properties of sinterhardened P/M materials. Advances in Powder Metallurgy \& Particulate Materials. 1998;3(I2): I19.

8 Engström U, Milligan D, Bengtsson S, Bergmark A, Maroli B, Frasier R. Evaluating the effects of mass and density on the sinterhardening response of different PM steels. San Diego: PowderMet; 2006.

Recebido em: 17 Jun. 2018

Aceito em: 14 Fev. 2020 